\title{
Structural Crystalline Development of Polyester Fibre Pretreated with Organic Solvents using XRD
}

\author{
Adeakin O.A.S., Ogunleye C.O., Alebiosu S.O. \\ Department Of Polymer And Textile Technology, \\ Yaba College Of Technology, Lagos.
}

\begin{abstract}
The development of crystalline and crystal size structure of a polyethylene terephthalate were studied after pretreatment of the polymer in ten organic solvents at $50^{\circ} \mathrm{C}$ and compared with untreated sample. The development of crystalline regions and crystal sizes were obtained. Samples treated in Benzyl alcohol having a solubility parameter nearest to that of the polymer was found to develop higher crystalline structures than that of other solvents. The crystalline content of the samples were determined from their respective diffactograms by evaluating the integrated scattering intensities. while the crystalline sizes were calculated using scherrers equation. even though the samples used were already texturized between $180^{\circ} \mathrm{C}$ and $200^{\circ} \mathrm{C}$, crystallite domains were established. small crystals were found to have fused to form bigger crystals.
\end{abstract}

\section{INTRODUCTION}

Polyester fibre is a semi crystalline polymer and the degree of crystallinity depends upon a number of factors such a drawing ratio, molecular weight and some mechanical parameters to which it is subjected to during production. The physical state and morphorlogical characteristics of polyester have a strong influence on its mechanical properties. A well orticulated technique of structural analysis of polymeric materials have been opened by using different methods and instrumental techniques such as XRD, SEM, DSC and Instron as reported by Bal 2006.

In his work solubility parameters concepts - a new look by Daniel Jr (1989), he is of the opinion that the concept is only suitable for predicting the simplest elastomers/fluid interactions Barton's recent work "Handbook of Solubility Parameters and other Cohesion Parameters" offers a starting point for a more detailed study.

Jensen 1986 correctly noted that most of the solubility parameter concepts used the historic similarity matching of properties rather than the more appropriate complementary matching of properties.

Hinderbrand gives the solubility parameter relationship as

$$
\delta=(\mathrm{CED})^{1 / 2}={ }^{{ }^{\Delta}} \mathrm{E}_{\mathrm{V}}{ }^{1 / 2}{ }^{\Gamma}=\left(\frac{\mathrm{cal}}{3}\right)^{1 / 2}
$$

Where CED = cohersive energy density, a measure of the strength of the intermolecular forces holding the molecules together in the liquid state

${ }^{\Delta} \mathrm{E}_{\mathrm{V}}=$ molar change in internal energy of vaporization $\mathrm{cal} / \mathrm{g}$ mole

$\mathrm{v}=$ molar volume of liquid $\mathrm{cm}^{3} / \mathrm{g}$ mole (Hinderbrand 1949)

Polyethylene terephthalate has a variety of usage and has become a very versatile polymer in engineering, medical, textile and so on. The application of solvents have been found to influence the development of crystal structures i.e. sizes, shapes, orientation and density of crystalline regions. The use of XRD x-rays diffraction machine is capable of revealing the level of crystalline development as a result of treatment of the polymer in ten solvents having solubility parameters near each other, leading to penetration of solvent into tighter or more compact areas. In other words the materials located in a more compact region where the solvent is less accessible at low temperature can become soluble with increasing temperature. Moore and Sheldon 1961 observed that the nature, polarity type, solubility parameter and molecular size of a solvent were the governing factors for both the equilibrium swelling and sizes.

It was further suggested that the non-polar hexane and carbon tetrachloride did not induce crystallinity and so also ethanol and n- butanol. The present study exposes the modification possible when polyester is pretreated in solvents at different temperatures to show a development of crystal sizes and also the d-spacing possible.

\section{MATERIALS AND METHODS}

Polyethylene terephthalate filament fibre obtained from a textile mill in Lagos was solvent treated at $50^{\circ} \mathrm{c}$ using a 3 neck solvent treatment flask. The solvents are chloroform, n-hexane, nitrobenzene, cychlorohexane, beuzaldehyde, dimethyl-o-phthalate, incresol, benzylalcohol, dimethylformamide, acetone. The treatment time was 120 seconds. they have different solubility parameter values

An XRD machine was used to determine the degree of crystalline development each of the solvent pretreated samples.

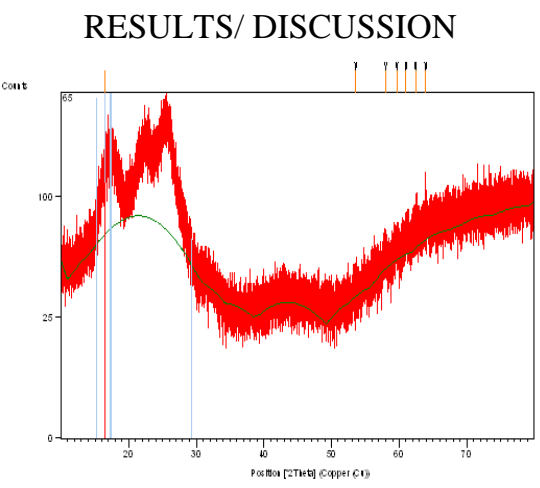

Fig 1 (Control) 


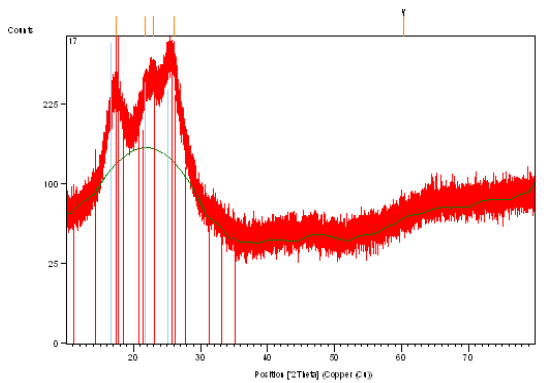

Fig 2 (Chloroform)

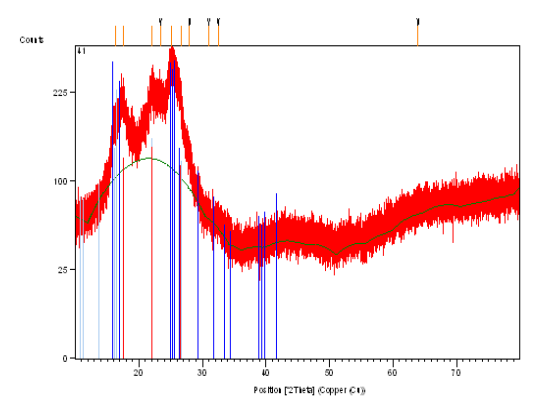

Fig 3 (Acetone)

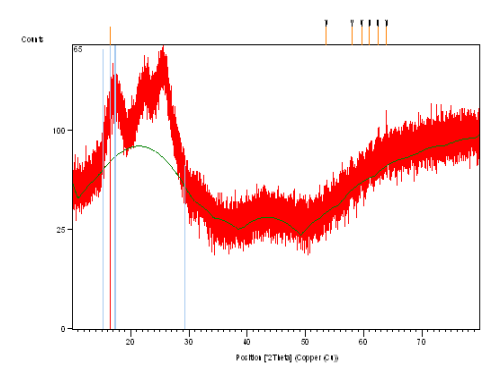

Fig 4 (Benzenaldehyde)

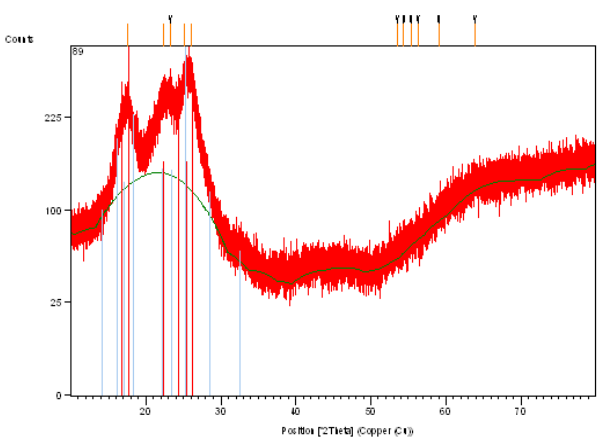

Fig 5 (Nitrobenzene)

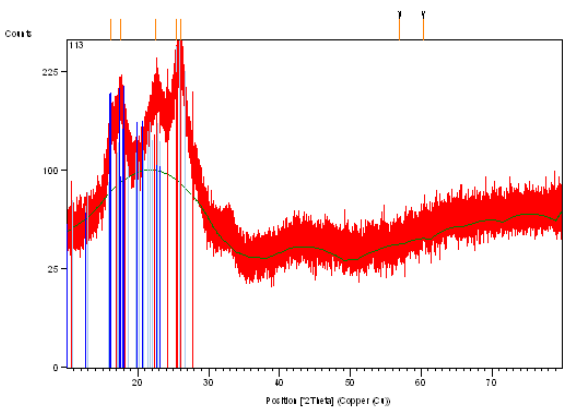

Fig 6 (Cyclohexane)

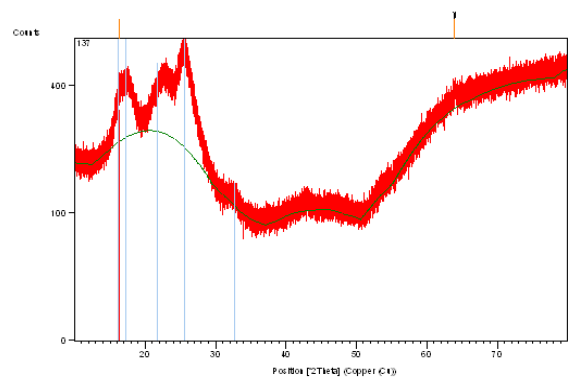

Fig 7 (Dimethyl-O-Phthalate)

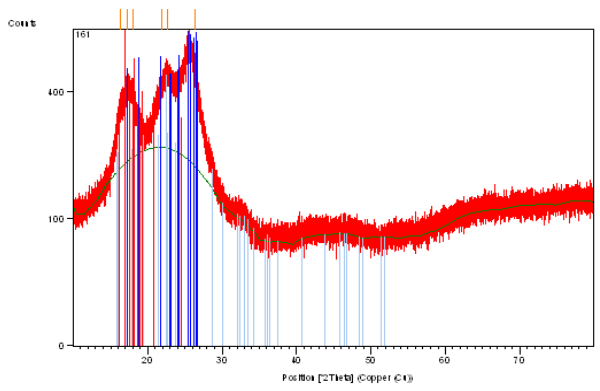

Fig 8 ( Dimethylforamide)

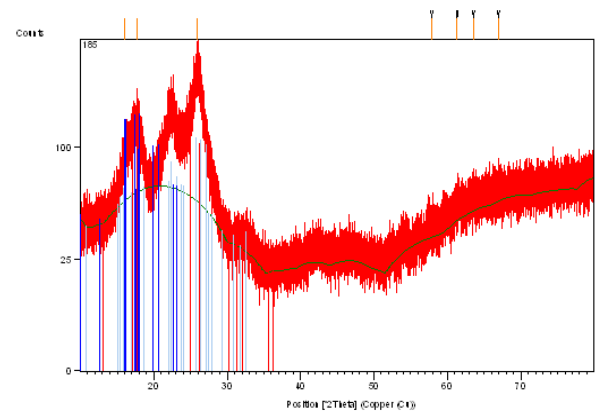

Fig 9 (Benzyl Alcohol)

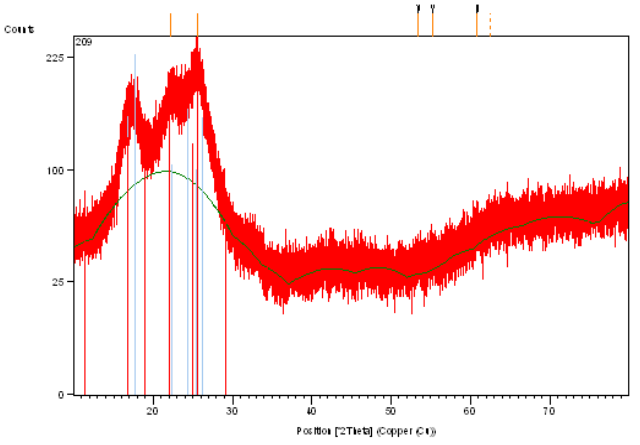

Fig 10 ( Mcrezol)

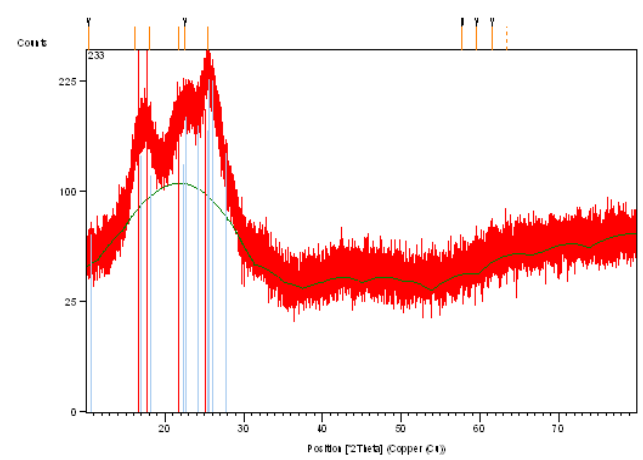

Fig 11 ( N-Hexane) 
Table 1: EFFECT OF VARIOUS SOLVENT PRETREATMENT ON CRYSTALLITE SIZE AND D- SPACING DEVELOPMENT FOR XRD

\begin{tabular}{|c|c|c|c|c|c|c|}
\hline $\begin{array}{c}\text { Solvent } \\
\text { Samples }\end{array}$ & $\begin{array}{l}\text { Solubility } \\
\text { Parameter }\end{array}$ & $\begin{array}{l}\text { Peak } \\
\text { No }\end{array}$ & $\begin{array}{c}2 \varnothing \\
\text { Degrees }\end{array}$ & $\begin{array}{c}\Delta \mathrm{W}= \\
\emptyset_{2}-\emptyset_{1} / \\
2\end{array}$ & $\begin{array}{l}\text { Braggs Spacing } \\
\mathrm{d}=\mathrm{n} \emptyset / \\
2 \sin \emptyset \\
\end{array}$ & $\begin{array}{l}\text { Crystallite Size } \\
\mathrm{t}=\frac{0.9 \lambda}{\Delta \mathrm{W} \cos \varnothing} \mathrm{O} \\
\mathrm{A}\end{array}$ \\
\hline \multirow{3}{*}{$\begin{array}{l}\text { *CONTROL } \\
\text { (UNTREATED SAMPLE) }\end{array}$} & \multirow{3}{*}{10.7} & 1 & 17.5 & 2.50 & 5.069 & 36.85 \\
\hline & & 2 & 22.3 & 0.85 & 3.986 & 93.50 \\
\hline & & 3 & 25.4 & 1.11 & 3.506 & 71.61 \\
\hline \multirow{3}{*}{ CHLOROFORM } & \multirow{3}{*}{9.3} & 1 & 15.2 & 2.40 & 5.829 & 33.12 \\
\hline & & 2 & 22.7 & 1.25 & 3.917 & 63.59 \\
\hline & & 3 & 25.9 & 1.15 & 3.440 & 69.12 \\
\hline \multirow[t]{3}{*}{ ACETONE } & \multirow{3}{*}{9.6} & 1 & 15.5 & 3.00 & 5.717 & 26.00 \\
\hline & & 2 & 23.4 & 0.75 & 3.802 & 90.21 \\
\hline & & 3 & 25.6 & 1.45 & 3.480 & 54.01 \\
\hline \multirow[t]{3}{*}{ BENZALDEHYDE } & \multirow{3}{*}{9.65} & 1 & 14.4 & 1.30 & 5.754 & 61.14 \\
\hline & & 2 & 21.9 & 0.45 & 4.058 & 76.63 \\
\hline & & 3 & 25.3 & 1.10 & 3.520 & 72.26 \\
\hline \multirow[t]{3}{*}{ NITROBENZENE } & \multirow{3}{*}{10} & 1 & 14.4 & 2.70 & 5.754 & 29.44 \\
\hline & & 2 & 22.8 & 1.15 & 3.901 & 69.12 \\
\hline & & 3 & 25.5 & 1.25 & 3.494 & 63.59 \\
\hline \multirow[t]{3}{*}{ CYCLOHEXANONE } & \multirow{3}{*}{10.4} & 1 & 14.6 & 2.85 & 6.608 & 27.89 \\
\hline & & 2 & 22.5 & 1.70 & 3.952 & 46.76 \\
\hline & & 3 & 25.5 & 0.95 & 3.493 & 83.67 \\
\hline \multirow{3}{*}{$\begin{array}{l}\text { DIMETHYL - O - } \\
\text { PHTHALATE }\end{array}$} & \multirow{3}{*}{10.4} & 1 & 15.4 & 2.85 & 5.754 & 27.89 \\
\hline & & 2 & 22.5 & 0.95 & 3.952 & 83.67 \\
\hline & & 3 & 25.6 & 1.65 & 3.480 & 48.17 \\
\hline \multirow{3}{*}{ D.M.F } & \multirow{3}{*}{11.8} & 1 & 15.4 & 2.9555 & 5.754 & 26.94 \\
\hline & & 2 & 22.8 & 1.00 & 3.900 & 79.48 \\
\hline & & 3 & 25.4 & 0.95 & 3.506 & 83.67 \\
\hline \multirow{3}{*}{ BENZYL ALCOHOL } & \multirow{3}{*}{12.1} & 1 & 14.3 & 2.30 & 6.195 & 34.56 \\
\hline & & 2 & 22.5 & 0.85 & 3.952 & 93.50 \\
\hline & & 3 & 25.6 & 0.75 & 3.480 & 98.98 \\
\hline \multirow{3}{*}{ Mcresol } & \multirow{3}{*}{14.6} & 1 & 15.5 & 2.00 & 5.717 & 39.74 \\
\hline & & 2 & 22.3 & 0.95 & 3.986 & 83.67 \\
\hline & & 3 & 25.7 & 0.85 & 3.467 & 93.30 \\
\hline \multirow{3}{*}{ nHEXANE } & \multirow{3}{*}{14.9} & 1 & 15.7 & 2.05 & 5.646 & 38.77 \\
\hline & & 2 & 23.0 & 0.95 & 3.867 & 83.67 \\
\hline & & 3 & 25.5 & 1.15 & 3.494 & 69.12 \\
\hline
\end{tabular}


Table 1 show the scattering diffract gram of untreated (control) and treated samples. The crystallite size has been calculated from its relationship with peak width at half maximum and the crystallinity content has been individually calculated from the scattering intensities after discounting scatterings due to the amorphous phase.

The crystalline content of the samples (A in \%) has been determined from respective diffractograms by evaluating the integrated scattering intensities. While the crystallite sizes have been calculated using Scherer equation;

$\mathrm{t}=\frac{0.9 \times \lambda}{\Delta \mathrm{W} \cdot \operatorname{Cos} \varnothing}$

The width $\Delta \mathrm{w}$ at half the maximum of crystalline peak was measured and the crystallite size was calculated as shown in diffractograms

Assuming the scattering powers of both the aliphatic and aromatic components are similar. The slight differences in the peak positions, intensity and diffuse maxima can be associated with the structural modification conferred on the polymer due to the stretching and the texturizing process and the level of solvents interaction on the polymer. This happens to be the major area of the present study. The d-spacing of the crystalline part of the polymer was calculated based on the Bragg equation:

$$
\text { i.e d }=\frac{\mathrm{n} \lambda}{2 \operatorname{Sin} \varnothing}
$$

$$
\begin{aligned}
& \mathrm{n}=\text { Order of reflection }(\mathrm{n}=1) \\
& \mathrm{d}=\text { Bragg's spacing } \\
& \varnothing=\text { Bragg's angle } \\
& \lambda=\text { Wavelength of the radiation }\left(1.542 \mathrm{~A}^{\circ}\right) .
\end{aligned}
$$

The results indicate that the crystallite size of the polyester are smaller in comparison to the untreated except for benzaldehyde $61.14 \mathrm{~A}^{\circ}$, benzyl alcohol $34.56 \mathrm{~A}^{\circ}$. m-cresol $39.74 \mathrm{~A}^{\circ}$, n-hexane $38.77 \mathrm{~A}^{\mathrm{o}}$. The increase obtained in the value for benzaldehyde may be attributed to the d-spacing for the treated samples which may be due to the overwhelming development of crystallites or that the smaller crystallites have aggregated together e.g for benzaldehyde which has $5.754 \mathrm{~A}^{\mathrm{o}}$, nitrobenzene $5.754 \mathrm{~A}^{\mathrm{o}}$, cyclohexanone $6.608 \mathrm{~A}^{\circ}$, dimethyl-o-phthalate $5.754 \mathrm{~A}^{\circ}$, dimethylformamide $5.754 \mathrm{~A}^{\circ}$, benzyl alcohol $6.195 \mathrm{~A}^{\circ}, \mathrm{m}$-cresol $5.717 \mathrm{~A}^{\circ}$ and n-hexane $5.646 \mathrm{~A}^{\circ}$ in the first peak.

From the result highlighted in figures $1-11$ and the table above, it is noted that even though the fibre used was already texturised between $180^{\circ} \mathrm{C}$ and $200^{\circ} \mathrm{C}$ crystalline domains were already established which were stable enough to resist further modification from the solvent treatment.(Silkstone, 1982)

The result obtained also shows that further modifications were detectable on the XRD for the polymer as pretreated in various solvents at $50^{\circ} \mathrm{C}$.

Small crystals were suspected to have fused to form bigger crystals, which created cavities or voids in the fibre structure. This could lead to increased amorphous volumes per crystals and hence more accessible regions for dye diffusion.

\section{CONCLUSION}

As a result of the pretreatment there were slight differences in the peak positions, intensity and diffuse maxima which can be associated with structural modification conferred on the polymer due to the stretching and the texturising process and the level of solvent interaction on the polymer. Small crystals which created cavities or voids in the fibre structure.

\section{REFERENCE}

[1] Bal, S. and Behera, R. C. (2006) Structural Investigation of Chemical Treated. Polyester fibres using SAXs and other techniques, Journal of Materials and Material Characterisation and Engineering. 5 (2); 179 - 199

[2] Bar, A. F. M. (1983). Handbook of solubility Parameters and other Cohesion Parameters, 20.

[3] Bendak, A. and El-Marsafi, S. M, (1991) Effect of Chemical Modification on Polyester Fibres. Journals of Islamic Academy of Sciences. pp 275-284

[4] Daniel, L H Jr (1989) Solubility Parameter Concepts A new look.

[5] Hinderbrand, H. and Scott, M. G. (1949). The Solubility of Non-electrolytes $3^{\text {rd }}$ Edition Reinhold New York.

[6] Jensen, W. S. (1987) Surface and Colloids Science in Computer Technology K.L. Mittal, Editor, Plenum Press New York

[7] Moncreiff, R. W. (1982) Man-made Fibres $6^{\text {th }}$ Edition Butterwork Scientific London, pp 436

[8] Moore, D. M and Reynolds, R. C. (1997) X-Ray Diffraction and the identification and Analysis of Clay Materials. $2^{\text {nd }}$ Edition Oxford University Press New York pp

[9] Moore, W. R. and Sheldon R.P., (1961), Liquid-induced Crystallisation in Polymer-Nature. Pp315

[10] Silkstone, K. (1982) The Influence of Polymer Morphology on Dyeing Properties of Synthetic Fibres Review Progress in Colouration pp12.

[11] Sheldon, R. P. (1962) kinetic study of Benzene - induced crystallisation of Polyethylene Terephthalate. Pp 27 - 34

[12] Reneker, D. H. (1960) Crystals of Linear Polyethylene growth from a solution of Perchloroethylene Journals of Applied Physics, 31

[13] Wakida, T. A. and Kuroki, G. (1975) sen - I p31, T 451 